\title{
Opinion and Special Articles: Self-management in epilepsy
}

Web-based seizure tracking applications

Charles Casassa, MD, Elle Rathbun Levit, MD, and Daniel M. Goldenholz, MD, PhD

Neurology ${ }^{\circledR}$ 2018;91:e2027-e2030. doi:10.1212/WNL.0000000000006547

What is the best way to engage patients with epilepsy? Patients and practitioners may have different answers to this question, but both would agree that having accurate information is of utmost importance. Benefits of electronic seizure diary systems include more efficient, timestamped data entry and the ability to generate graphical summaries. Limitations include the need for some degree of digital sophistication on the part of the patient or caregiver, the cost of the underlying electronic platform, the requirement for ongoing patient/caregiver engagement, and the potential for privacy issues with data entry. ${ }^{1,2}$

In the midst of a busy neurology clinic day, it is critical to obtain accurate information efficiently. Consider a patient with drug-resistant epilepsy whose caregivers provide conflicting information about recent seizure history. With a digital diary, both patients and providers can rapidly review the pertinent data in a summarized format, reconcile differences, and address next steps. Together, the patient, providers, and caregivers can use this information to formulate an individualized seizure management plan.

A number of free epilepsy mobile tools are available for use by patients and providers. Here, we review 3 widely used applications. Recently, common standards for mobile epilepsy apps have been developed, so there are many features in common among them. ${ }^{3,4}$ Each app provides patients with an interface to track their seizures and share information with caregivers and health care providers. Patients can input many characteristics of their seizures and can include the presence of aura, duration, triggers, event and postevent descriptors, and rescue medications used. Patients also have the option to freely enter text about the seizure. All allow for generation of graphical summaries to examine trends over time, in addition to a number of other features. We have included a table for comparison among the applications (table).

\section{SeizureTracker}

SeizureTracker was created by Robert Moss nearly 10 years ago, inspired by his son's experience with drug-resistant epilepsy. The platform includes the SeizureTracker website and its corresponding iOS and Android app, "Track It!"

SeizureTracker offers a clear interface with few superfluous features. We found its graphical summary reports to be among the most informative relative to other similar applications, allowing for details such as medication dose changes to be clearly marked on the charts (figure 1).

Two aspects of SeizureTracker are especially remarkable: its incorporation of voice-activated technology and unique within-app features. Such features include a women's issues tool, which includes menstrual cycle tracking (and soon will have a birth control/pregnancy feature), and a diet function for detailed diet entry in relation to seizure activity. The application also includes
Correspondence Dr. Rathbun Levit erathbun@

bidmc.harvard.edu 
Table Comparison of features among the 3 reviewed applications

\begin{tabular}{|c|c|c|c|}
\hline & SeizureTracker & $\begin{array}{l}\text { Epilepsy Foundation My Seizure } \\
\text { Diary }\end{array}$ & EpiDiary \\
\hline Ease of use & Moderate & More challenging & Easy \\
\hline $\begin{array}{l}\text { Rating on app store (out of } 5 \text { stars) as of May } \\
6,2018\end{array}$ & iOS: 4.5; Android: 4 & iOS: 2.5; Android: 2 & iOS: 5; Android: 3.5 \\
\hline Seizure logging & $\checkmark$ & $\checkmark$ & $\checkmark$ \\
\hline Medication regimen & $\checkmark$ & $\checkmark$ & $\checkmark$ \\
\hline Daily medication adherence & & $\checkmark$ & $\checkmark$ \\
\hline Graphical reports & $\checkmark$ & $\checkmark$ & $\checkmark$ \\
\hline Share with health care providers & $\checkmark$ & $\checkmark$ & $\checkmark$ \\
\hline Compatibility & $\begin{array}{l}\text { Website, iOS, Android, Watch OS, Amazon } \\
\text { Alexa }\end{array}$ & Website, iOS, Android & $\begin{array}{l}\text { Website, iOS, } \\
\text { Android }\end{array}$ \\
\hline Built-in reminder system & & $\checkmark$ & $\checkmark$ \\
\hline Vagus nerve stimulator settings & $\checkmark$ & & \\
\hline Recording information for seizure-free days & & $\checkmark$ & $\checkmark$ \\
\hline YouTube video directly linked to seizures & $\checkmark$ & & $\checkmark$ \\
\hline Pictures of pills in app & & & $\checkmark$ \\
\hline
\end{tabular}

a vagus nerve stimulator (VNS) input, which permits patients to enter their VNS settings and record VNS usage. Finally, SeizureTracker offers Amazon Alexa capability; patients can say, "Alexa, I'm having a seizure" and have the seizure recorded instantly.

A limitation of SeizureTracker is that the application currently does not allow reporting of seizure-free days. This omission makes it more difficult for patients, caregivers, and clinicians to know if a day was seizure-free or simply not recorded.

\section{Epilepsy Foundation My Seizure Diary}

Epilepsy Foundation My Seizure Diary, formerly known simply as My Seizure Diary, is available through the Epilepsy Foundation. This platform includes a web application and mobile apps for iOS and Android.

The data entry within Epilepsy Foundation My Seizure Diary allows for a substantial level of detail. For example, when a patient enters seizure information, the patient is prompted

Figure 1 A sample report details a patient's recent seizure history, subdivided by patient's seizure type, in relation to time and recent medication dosing changes, from SeizureTracker

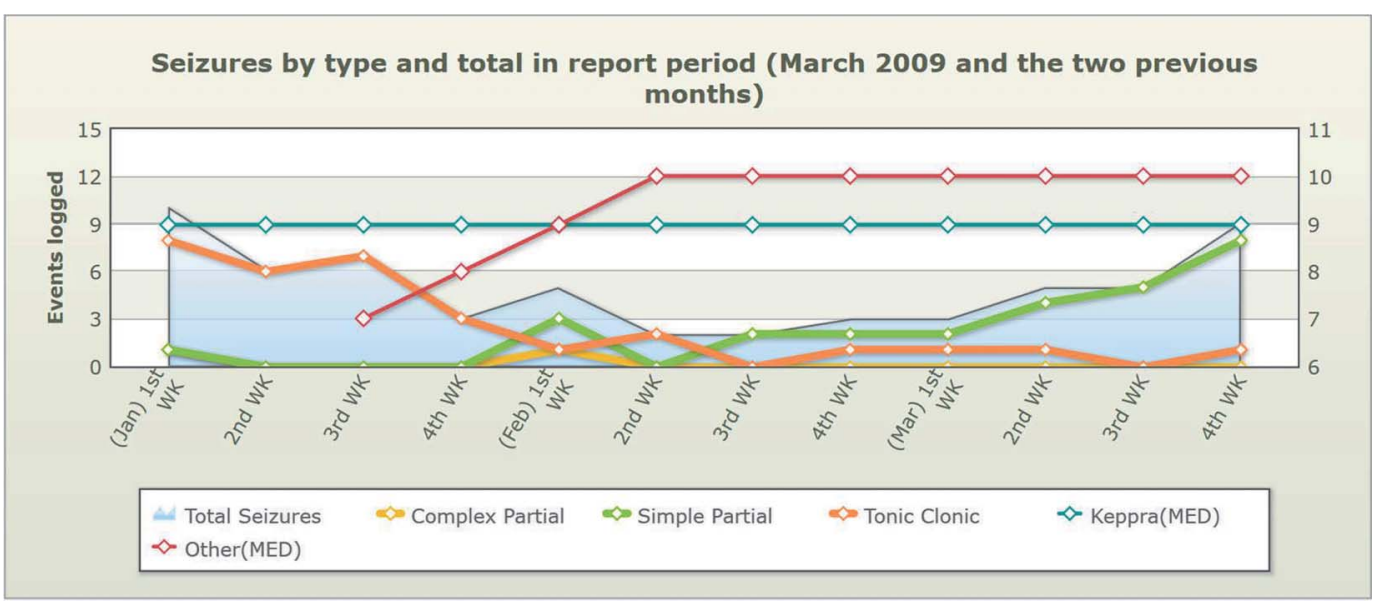

Reprinted with permission. 
Figure $2 \mathrm{~A}$ sample data entry screen for seizure type, with the components of the main dashboard to the left, from Epilepsy Foundation My Seizure Diary

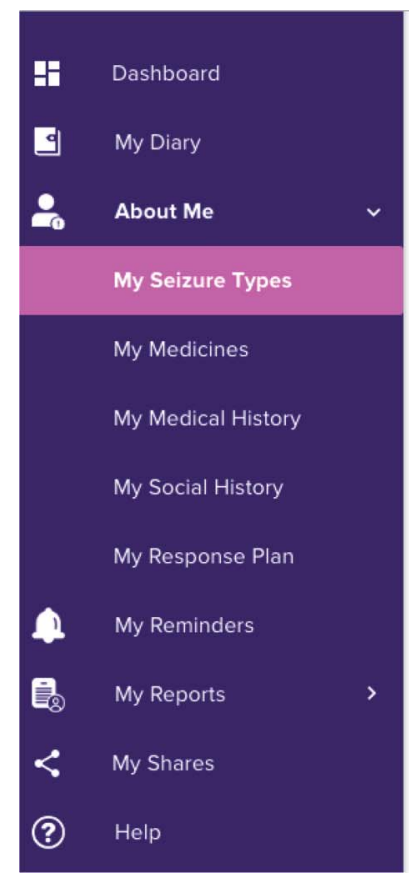

\section{New Seizure Type}

Give a name to this type of seizure

How does the seizure start?

Briefly describe what happens during the seizure

How long does the seizure last?

Frequency

x Time unit

What happens after the seizure?

How long does recovery last?

Reprinted with permission.

Figure 3 The graphic-based interface of EpiDiary, with examples of notations to indicate pertinent events, such as changes in sleep pattern, mood, and seizure-free days

\section{My Diary}

Click on a date in the Diary or select a day below:

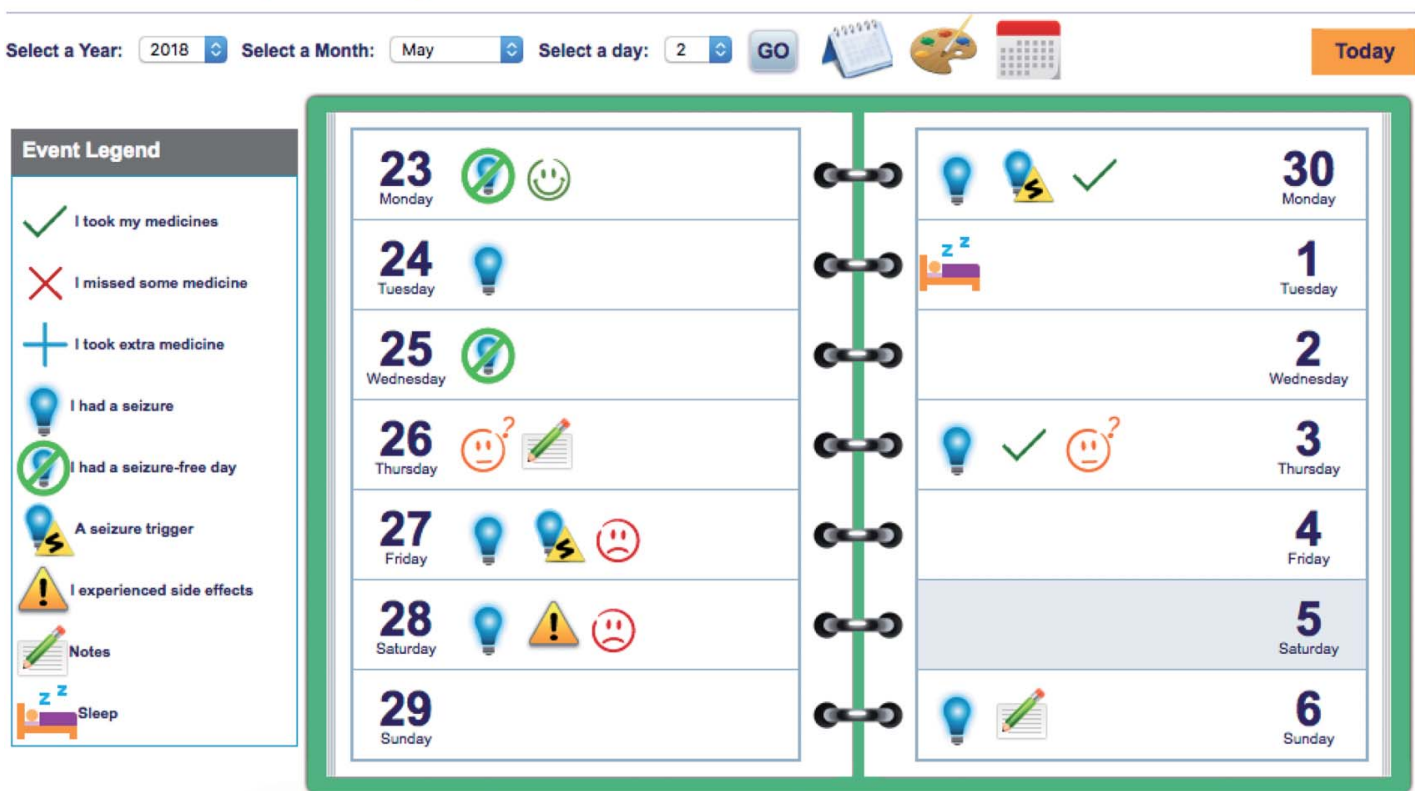

Previous week

Reprinted with permission. 
to enter not just basic seizure characteristics, but also specific details, such as the duration of the postictal period and whether this seizure type has a corresponding physician diagnosis (figure 2). The latter can be particularly helpful for providers in an inpatient setting to determine which events carry a specific diagnosis, particularly in patients who have both epileptic seizures and psychogenic nonepileptic seizures. Videos can be uploaded to the diary as attachments, but not directly linked to seizures.

One special feature of Epilepsy Foundation My Seizure Diary is its associated real-time online community. This robust resource includes a spectrum of services, ranging from technologic support to assistance with identifying Foundationidentified resources and helplines to a moderated online chat feature. Patients have a venue to connect with others who share similar experiences, in a setting that is aimed at providing the most accurate information possible. Patients and providers should be aware that while the forum and article posts are reviewed periodically, The Epilepsy Foundation does not provide $24 / 7$ monitoring of these features.

We felt that the user interface of Epilepsy Foundation My Seizure Diary was more complex relative to other similar applications, and more time was required initially to gain familiarity with its features. This learning curve could potentially serve as a barrier to use for less digitally sophisticated users.

\section{EpiDiary}

Provided through Irody, Inc., EpiDiary is another widely used self-management platform, available for use through its website, iOS, and Android.

From the moment one opens EpiDiary, its appealing graphicbased style jumps out at the user. Patient-entered information is laid out in an accessible format with visual annotations to draw attention to patient-entered elements on the calendar interface, such as a face to indicate mood and checks to note medication compliance (figure 3 ).

As providers, we often encounter patients who identify medications by their appearance. Patients often recall the color, size, shape, and form (pill, tablet) of a medication but have difficulty connecting this image to the medication name. Irody uses a mnemonic by allowing patients to capture a photograph of their pill and displays it in the app. This resource becomes increasingly important if a medication's appearance changes over time, such as when suppliers of generic medications change.

Irody has also developed "pill recognition technology," which can identify medications by their appearance and compare it to the prescription. "One-click medication reminders" can prompt patients to take the correct medication at the correct time with the medication image incorporated into the lock screen of their phone.

While these are useful features, they are not currently available to all users. Pill recognition technology is currently available for clinical studies only. One-click medication reminders are accessible in Android only at present.

\section{Discussion}

Overall, the goal of web-based seizure tracking applications is to empower people to take charge of their health by being proactive in their care, and allowing them to manage their data in a user-friendly application. SeizureTracker, Epilepsy Foundation's My Seizure Diary, and EpiDiary are all examples of web self-management tools that have the potential to be helpful means to facilitate accurate data collection, which in turn aids physicians in clinical decision-making. While the reviewed applications share a similar aim, the interfaces and certain features differentiate how each application achieves these goals. Because these tools are free, patients have the opportunity to try each one and find the platform that can best serve their needs.

\section{Author contributions}

C. Casassa: drafting/revising the manuscript, data acquisition, study concept or design, accepts responsibility for conduct of research and final approval, acquisition of data. E. Rathbun: drafting/revising the manuscript, data acquisition, accepts responsibility for conduct of research and final approval, interviewing developers of apps discussed in article. D.M. Goldenholz: drafting/revising the manuscript, data acquisition, study concept or design, analysis or interpretation of data, accepts responsibility for conduct of research and final approval, acquisition of data, study supervision.

\section{Acknowledgment}

The authors thank Robert Moss of SeizureTracker, Eyal Bartfield of EpiDiary, and Patricia Shafer of the Epilepsy Foundation for providing background on their applications to the authors.

\section{Study funding}

No targeted funding reported.

\section{Disclosure}

The authors report no disclosures relevant to the manuscript. Go to Neurology.org/N for full disclosures.

\section{References}

1. Fisher RS, Blum DE, DiVentura B, et al. Seizure diaries for clinical research and practice: limitations and future prospects. Epilepsy Behav 2012;24:304-310.

2. Scheherazade L, Shafer PO, Bartfield E, Fisher RS. An online diary for tracking epilepsy. Epilepsy Behav 2011;22:705-709.

3. The National Institute of Neurological Disorders and Stroke (NINDS). Seizure Diary. In: NINDS Common Data Elements [online]. Available at: commondataelements. ninds.nih.gov/epilepsy.aspx\#tab=Data_Standards. Accessed May 6, 2018.

4. Goldenholz DM, Moss R, Jost DA, et al. Common data elements for epilepsy mobile health systems. Epilepsia 2018;59:1020-1026. 


\section{Neurology}

\section{Opinion and Special Articles: Self-management in epilepsy: Web-based seizure tracking applications \\ Charles Casassa, Elle Rathbun Levit and Daniel M. Goldenholz \\ Neurology 2018;91;e2027-e2030 \\ DOI 10.1212/WNL.0000000000006547}

This information is current as of November 19, 2018

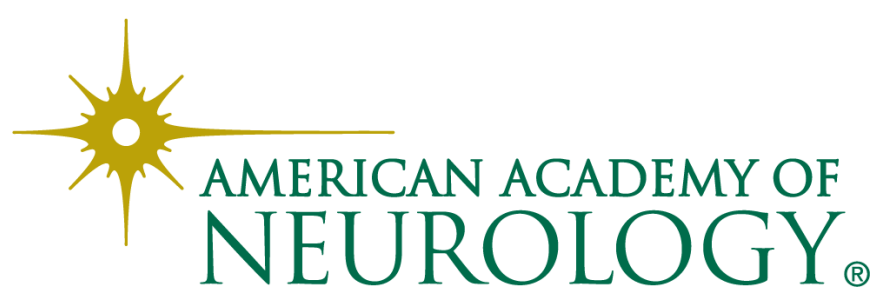




\section{Updated Information \& Services}

References

Citations

Subspecialty Collections

Errata

Permissions \& Licensing

\section{Reprints}

including high resolution figures, can be found at: http://n.neurology.org/content/91/21/e2027.full

This article cites 3 articles, 0 of which you can access for free at: http://n.neurology.org/content/91/21/e2027.full\#ref-list-1

This article has been cited by 1 HighWire-hosted articles: http://n.neurology.org/content/91/21/e2027.full\#\#otherarticles

This article, along with others on similar topics, appears in the following collection(s):

All Epilepsy/Seizures

http://n.neurology.org/cgi/collection/all_epilepsy_seizures Clinical neurology history

http://n.neurology.org/cgi/collection/clinical_neurology_history

EEG; see Epilepsy/Seizures

http://n.neurology.org/cgi/collection/eeg_see_epilepsy-seizures

Epilepsy monitoring

http://n.neurology.org/cgi/collection/epilepsy_monitoring_ Epilepsy semiology

http://n.neurology.org/cgi/collection/epilepsy_semiology

An erratum has been published regarding this article. Please see next page or:

/content/93/9/415.2.full.pdf

Information about reproducing this article in parts (figures,tables) or in its entirety can be found online at:

http://www.neurology.org/about/about_the_journal\#permissions

Information about ordering reprints can be found online:

http://n.neurology.org/subscribers/advertise

Neurology ${ }^{\circledR}$ is the official journal of the American Academy of Neurology. Published continuously since 1951, it is now a weekly with 48 issues per year. Copyright @ 2018 American Academy of Neurology. All rights reserved. Print ISSN: 0028-3878. Online ISSN: 1526-632X.

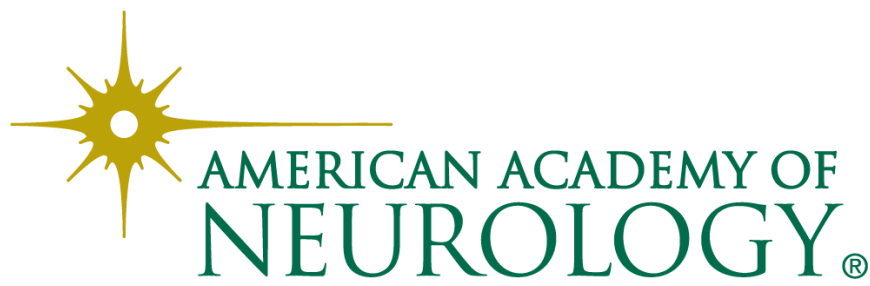




\section{Teaching NeuroImages: The zigzag edging sign of adult-onset neuronal intranuclear inclusion disease}

Neurology ${ }^{\circledR}$ 2019;93:415. doi:10.1212/WNL.0000000000007922

In the article "Teaching NeuroImages: The zigzag edging sign of adult-onset neuronal intranuclear inclusion disease" by Chen et al., ${ }^{1}$ the second-to-last sentence in the first paragraph should read "FMR1 CGG permutation was not present." The publisher regrets the error.

\section{Reference}

1. Chen L, Chen A, Lei S, et al. Teaching NeuroImages: The zigzag edging sign of adult-onset neuronal intranuclear inclusion disease. Neurology 2019;92:e2295-e2296.

\section{Opinion and Special Articles: Self-management in epilepsy}

Web-based seizure tracking applications

Neurology ${ }^{\circledR}$ 2019;93:415. doi:10.1212/WNL.0000000000007480

In the article "Opinion and Special Articles: Self-management in epilepsy: Web-based seizure tracking applications" by Casassa et al., ${ }^{1}$ first published online November 19, 2018, NIH Grant T32NS048005 should have been listed as a funding source. The authors regret the error.

\section{Reference}

1. Casassa C, Rathbun Levit E, Goldenholz DM. Opinion and Special Articles: Self-management in epilepsy: web-based seizure tracking applications. Neurology 2018;91:e2027-e2030.

\section{Cost of illness in Charcot-Marie-Tooth neuropathy}

Results from Germany

Neurology ${ }^{\circledR}$ 2019;93:415. doi:10.1212/WNL.0000000000007916

In the article "Cost of illness in Charcot-Marie-Tooth neuropathy: Results from Germany" by Schorling et al., ${ }^{1}$ first published online March 27, 2019, the published-online-ahead-of-print version should have presented figures in USD rather than euros. They are presented correctly in the April 23 issue. The editorial office regrets the error.

\section{Reference}

1. Schorling E, Thiele S, Gumbert L, et al. Cost of illness in Charcot-Marie-Tooth neuropathy: results from Germany. Neurology 2019;92: e2027-e2037.

\section{Comprehensive systematic review summary: Treatment of tics in people with Tourette syndrome and chronic tic disorders Neurology ${ }^{\circledR}$ 2019;93:415. doi:10.1212/WNL.0000000000007918}

In the article "Comprehensive systematic review summary: Treatment of tics in people with Tourette syndrome and chronic tic disorders" by Pringsheim et al., ${ }^{1}$ first published online May 6, 2019, the data supplement link in the first paragraph should have been: links.lww.com/ WNL/A882. The authors regret the error.

\section{Reference}

1. Pringsheim T, Holler-Managan Y, Okun MS, et al. Comprehensive systematic review summary: Treatment of tics in people with Tourette syndrome and chronic tic disorders. Neurology 2019; 92:907-915. 